Revista Mídia e Cotidiano

Artigo Seção Livre

Volume 12, Número 2, agosto de 2018

Submetido em: 05/05/2018

Aprovado em: 06/08/2018

\title{
TERRA DOIS E A ANTECIPAÇÃO DA EXPERIÊNCIA COM VIÉS LACANIANO
}

\section{TERRA DOIS AND THE ANTICIPATION OF EXPERIENCE: A LACANIAN APPROACH}

\author{
Carlos Alberto ZANOTTI ${ }^{1}$, Hebe Rios do CARMO $^{2}$
}

\section{Resumo:}

Considerado o melhor programa de televisão no ano de 2017 pelos críticos de arte do Estado de São Paulo, o seriado Terra Dois, da TV Cultura, se propõe a debater experiências de vida sob o paradigma da chamada pós-modernidade. Para tanto, aproxima teledramaturgia e divulgação científica, fazendo com que cada episódio enseje um estudo de caso sob o viés da psicanálise lacaniana. Este artigo se propõe a debater a experiência comandada pelo psicanalista Jorge Forbes, observando as funções inerentes aos sistemas sociais mobilizados na produção televisiva. Para tanto, o método aqui adotado inclui pesquisa bibliográfica, entrevista e análise textual discursiva de um de seus episódios. O resultado indica que o seriado propõe ao seu público a adesão resiliente a um conjunto de valores, embora mitigue a crítica às relações de poder que permeiam as experiências de vida.

Palavras-chave: Mídia e identidade; Terra Dois; televisão; organização sistêmica; comunicação científica.

\begin{abstract}
:
Considered the best TV program in the year 2017 by art critics of the State of São Paulo, the television series Terra Dois, on TV Cultura, proposes to discuss life experiences under the paradigm of the so-called postmodernity. In order to do so, it approximates television drama and scientific communication, making each episode a case study under the bias of Lacanian psychoanalysis. This article proposes to debate the television program commanded by the psychoanalyst Jorge Forbes, observing the functions inherent to the social systems mobilized in the television production. For this, the method adopted here includes the bibliographical research, the interview and the textual discursive analysis of one of its episodes. The result indicates that the series proposes to its public the resilient adhesion to a set of values, although it mitigates the critic to the relations of power that permeate the experiences of life.
\end{abstract}

Keywords: Media and identity; Terra Dois; Television series; Systemic theory; Scientific communication.

\footnotetext{
1 Doutor em Ciências da Comunicação pela Universidade de São Paulo. Professor do Programa de Pós-Graduação "Linguagens, Mídia e Arte" da PUC-Campinas e membro titular do Comitê de Ética em Pesquisa com Seres Humanos da PUC-Campinas (2016-2019). E-mail: zanotti@puc-campinas.edu.br.

2 Mestranda em Linguagens, Mídia e Arte pela Pontifícia Universidade Católica de Campinas. Email: hebe.rios.jornaista@gmail.com.
} 
eCl

DiAno

Introdução

O propósito deste trabalho é analisar uma produção midiática que articula distintos gêneros televisivos para explicar sentimentos e valores sociais que se anunciam como dominantes em um futuro próximo. Se os meios de comunicação contribuem decisivamente para ampliar nosso repertório de experiências (GIDDENS, 2002), o seriado Terra Dois, da TV Cultura de São Paulo, funciona como um mecanismo que busca antecipar esse repertório, como que educando seu público para uma revolução que já se iniciou nas sociedades pós-modernas. O seriado articula divulgação científica na área de Humanidades e entretenimento, buscando preparar seus espectadores para administrar choques geracionais que deverão surgir no novo paradigma.

As reflexões aqui apresentadas - parte inicial de um trabalho maior, em andamento - decorrem de pesquisas bibliográfica e documental, além de se ampararem em uma entrevista com o idealizador do seriado e promover a análise textual de um dos episódios, segundo as diretrizes de Casetti e Chio (1999). Adota-se, para tanto, um percurso que se apoia na abordagem sistêmica com que Luhmann (2005) observa a função dos meios de comunicação no sistema social. Neste trabalho, procuramos associar a formação lacaniana do criador do seriado, o psicanalista brasileiro Jorge Forbes, às concepções de pós-modernidade de autores como Giddens (2002) e Bauman (2001; 2009). Com tais instrumentos, buscamos realizar uma pesquisa de natureza descritiva que nos ajude a compreender a boa receptividade de Terra Dois junto a uma parcela da intelectualidade brasileira, embora a produção registre baixos índices de audiência no universo da TV aberta.

Comecemos por Luhmann. O sociólogo alemão oferece, a partir de sua obra, uma descrição do funcionamento da sociedade segundo uma teoria geral dos sistemas. Para ele, os seres humanos de todo o mundo formam um único sistema, o sistema social. Em seu processo organizativo, esse sistema comporta uma série de subsistemas que, em função de sua crescente complexificação, dá origem a novos sistemas ou subsistemas. Ou seja, a sociedade é, para o autor, caracterizada por funções diferenciadas que se manifestam na forma de subsistemas, como o político, o educacional, o científico, o religioso ou o jurídico. 
A comunicação - o nosso objeto de estudos - é entendida por Luhmann como sendo o operador central de todos os sistemas que compõem o sistema social. Isto porque, os sistemas sociais valem-se da comunicação para que possam efetuar operações inerentes às suas funções. Para tanto, fazem uso de meios técnicos, ou media (plural de medium), expressão mais adequada ao pensamento do autor de acordo com seu tradutor brasileiro. Bem por isso, na apresentação à obra $A$ realidade dos meios de comunicação, Marcondes Filho $(2005$, p. 9) ressalta que, para o autor alemão, “os meios de comunicação funcionam como medium que ligam comunicações criando conteúdos compreensíveis (formas).”.

A partir destes pressupostos luhmaniannos, entendemos que a emissora de televisão em questão - componente que integra o que conhecemos por sistema midiático - produz formatações quando cria um determinado programa para comunicar as comunicações de outro sistema - o científico -, mais especificamente aquele voltado a desvendar a dimensão psicológica presente no sistema social, neste caso segundo o viés lacaniano. Temos então, por meio dos meios de comunicação, os sistemas observam-se a si e aos outros sistemas e realizam, como diz Luhmann, a atividade de desenvolver e formatar "operações observadoras" a respeito do sistema social.

Entre as operações observadoras incluímos o seriado Terra Dois, cuja formatação resulta da sobreposição de duas das três tipologias clássicas com que Luhmann classifica os conteúdos dos meios de comunicação. No seriado da TV Cultura, observa-se o hibridismo de jornalismo (de divulgação científica) e entretenimento. Colocamos sob a designação de jornalismo não necessariamente os conteúdos (notícia e reportagens) considerados por Luhmann (2005, p. 51), mas sim a atualidade e a universalidade da temática que sustenta a série, bem como a utilização de técnicas e estratégias comunicacionais tradicionalmente adotadas pelos profissionais de imprensa, como a entrevista e a inserção de imagens de acontecimentos reais.

Enquanto operação observadora realizada por um viés do sistema científico, a comunicação aqui produzida se destina ao meio técnico que se encontra no cerne da chamada "cultura da mídia", a televisão, conforme aponta o filósofo Douglas Kellner, investigador do campo dos estudos culturais. Trata-se, segundo este autor, de uma cultura capaz de produzir "novos tipos de sociedade em que mídia e tecnologia se 
tornam seus princípios organizadores" (KELLNER, 2001, p. 10). Kellner sugere que a televisão contemporânea roubou do mito e do ritual a função de "integrar os indivíduos numa ordem social" ao celebrar valores dominantes e oferecer "modelos de pensamento, comportamento e sexo para imitação" (KELLNER, 2001, p. 304). Diz o autor:

[...] a cultura da mídia põe à disposição imagens e figuras com as quais seu público pode identificar-se, imitando-as. Portanto, ela exerce importantes efeitos socializantes e culturais por meio de seus modelos de papéis, sexo e por meio de várias 'posições de sujeito' que valorizam certas formas de comportamento e modo de ser enquanto desvalorizam e denigrem outros tipos." (KELLNER, 2001, p. 307)

Já o sociólogo britânico Anthony Giddens (2002) observa que a experiência canalizada nas produções dos meios de comunicação, desde a primeira experiência da escrita, tem influenciado tanto a autoidentidade quanto a organização das relações sociais. Para ele, a mídia amplia as experiências de seus públicos à medida que promove uma "intrusão de eventos distantes na consciência cotidiana" (GIDDENS, 2002, p. 31). A mídia o faz ao mobilizar "mecanismos de desencaixe" de tais experiências, descolando-as de seus lugares específicos e recombinando-as a grandes distâncias espaço-temporais. A reorganização do tempo e espaço, somada aos mecanismos de desencaixe "radicaliza e globaliza traços institucionais preestabelecidos da modernidade; e atua na transformação do conteúdo e da natureza da vida social cotidiana." (GIDDENS, 2002, p. 10). A intrusão a que se refere Giddens produziria, assim, uma familiaridade com experiências não vividas.

Entendemos que Terra Dois, em certa medida, muito contribui para antecipar experiências em um novo paradigma, trazendo para dentro da casa do espectador situações ainda não vividas nas interações cotidianas, ou seja, aquelas que independem de um meio técnico para ocorrer, feitas em regime de copresença (THOMPSON, 1998). E o faz de uma maneira muito singular, buscando recursos da dramaturgia que se somam à reflexão acadêmica para - a partir de uma entrevista com o especialista da área, um recurso do jornalismo - oferecer uma leitura organizada de mundo. Temos ali, portanto, um produto híbrido, que recorre a vários componentes que caracterizam o sistema midiático com a finalidade de antecipar experiências. 


\section{Cultura, Forbes e Lacan}

Em 21 de setembro de 2016, a estatal paulista TV Cultura conquistou título de rede nacional por alcançar ao menos $1 / 3$ da população do país e estar presente em mais de 2 mil municípios das cinco regiões brasileiras. Através de 90 emissoras afiliadas ou retransmissoras, a empresa tem hoje condições técnicas para atingir 125 milhões de brasileiros. Na Grande São Paulo, onde está sediada, registrou durante o ano de 2017 uma média diária de 1,1 pontos de audiência (FELTRIN, 2017). Cada ponto indica que em 70,5 mil domicílios havia ao menos um aparelho de televisão sintonizado na emissora. Entre as seis redes nacionais, ficou em penúltimo lugar em índice de audiência, à frente apenas da Rede TV. O seriado Terra Dois, que vai ao ar às quartasfeiras a partir das $22 \mathrm{~h} 30$, possui cerca de 0,2 ponto de audiência, o que implica em público estimado entre 30 mil e 40 mil espectadores no universo de 21,2 milhões de habitantes que compõe a base da sondagem.

Conforme a classificação proposta de Casetti e Odin (2012), a emissora paulista reúne elementos que a colocam na fase de desenvolvimento chamada neotelevisão. Isto significa que a emissora possui diversidade de gêneros em sua grade; seu espectador é chamado a intervir nos programas; possui um discurso que convida à proximidade; é descontraída em alguns momentos; e seus programas, de um modo geral, se ligam uns aos outros. Terra Dois, ao contrário, é uma produção típica da fase anterior, a da paleotelevisão, dominante no período compreendido entre sua criação do meio e os anos iniciais da década de 1980 e os anos iniciais da década de 1980. Foi uma etapa marcada pela distinção clara e hierarquizada entre emissor e receptor, quando prevaleceu o discurso institucional e prescritivo, ou seja, buscando criar um espaço para a formação cultural do espectador.

Recorrendo à classificação proposta por Aronchi (2006), Terra Dois resultaria da soma de dois distintos gêneros televisivos: a entrevista e a teledramaturgia. Estaríamos, portanto, frente a uma simbiose de jornalismo e entretenimento, resultado das observações que o sistema midiático produz a respeito das observações que o sistema especializado em psicologia social elabora por conta da mudança paradigmática em curso. Dada à ideia de complexificação, a psique é aqui reportada segundo o viés 
lacaniano, do qual Forbes se apropria para - na condução dos objetivos do programaaposentar o complexo de Édipo instaurado pelo "pai da psicanálise".

O formato do seriado assemelha-se a uma aula prática a respeito de temas do cotidiano impactados por valores, normas e estatutos que se imaginam dominantes em um tempo histórico que já teria se iniciado. No programa, esse tempo histórico, a todo o momento, é identificado como pós-modernidade pelo estudioso de Lacan. E ele o faz quando, instado por uma parceira de cena, comenta os dramas vividos por personagens de uma narrativa levada ao ar em formato de teledramaturgia. Com isso, antecipam-se reflexivamente experiências existenciais aos seus telespectadores. O cenário da produção é inspirado na estética de Dogville, longa-metragem dirigido pelo dinamarquês Lars Von Trier. E, nas narrativas dramatizadas, identificam-se elementos distópicos que fazem lembrar a série britânica Black Mirror, conforme reconhece o próprio Forbes (2017).

Ex-aluno de Jacques Lacan nos anos de 1976 a 1981, com doutorados em Teoria Psicanalítica, e Medicina e Neurologia, Forbes desenvolveu a tese de que a "clave edípica" que caracterizou a instalação da psicanálise se tornou "insuficiente para ler uma série de sintomas novos no consultório" (FORBES, 2017). Tais sintomas seriam fruto da transição de um período de relações sociais estáveis, sólidas e verticalizadas (família, trabalho, escola...) para uma estruturação horizontal e líquida (BAUMAN, 2001) decorrente da globalização na pós-modernidade.

Na mudança de época, do mundo moderno para o pós-moderno, você desestabiliza certezas estáveis, que eram dadas, no sentido filosófico, pelas características cartesianas de verdade. A problemática do ser humano na pós-modernidade não seria mais tanto o que o impede de chegar ao objetivo previamente traçado, mas, ao contrário, definir qual o objetivo a ser traçado uma vez que são muitas as possibilidades. (FORBES, 2017)

Visando decifrar o paradigma proposto, para o qual o psicanalista registrou a expressão Terra Dois, Forbes recorreu aos últimos trabalhos de seu professor francês, falecido em 1981, que se caracterizaram por uma etapa que os estudiosos da área convencionaram chamar de "segunda clínica" de Lacan. É descrita como uma espécie de "clínica do real", pois foca a atenção para o "inconsciente real", onde real não significa realidade, "mas algo que escapa a qualquer tentativa de captura simbólica". E 
que, pela impossibilidade de sua simbolização, estaria sempre presente, dando origem aos sintomas que levam à presença do analista (FORBES, 2017). Bem por isso, Terra Dois sustenta-se no que poderia ser chamado de "paradigma da incompletude".

\section{O medo que organiza}

Aqui buscaremos compreender os efeitos da participação do psicanalista Jorge Forbes quando explica e analisa as vivências ficcionais levadas ao ar no seriado. Visando preparar o público para uma convivência menos estressante no suposto novo paradigma, ele recorre a noções de pós-modernidade como vistas, principalmente, nos apontamentos de Bauman. Para tanto, adotaremos o método analítico recomendado por Casetti e Chio (2013) relativo às análises textuais. A estratégia, segundo os autores, pode ser aplicada a programas isolados ou ao conjunto de uma programação televisiva. A abordagem difere de apurações quantitativas, uma vez que

[...] não se trata de medir quantitativamente a presença de determinados temas, figuras ou ambientes, mas pôr em relevo a arquitetura e o funcionamento dos programas analisados, a estrutura teórica que os sustenta e as estratégias que adotam (as imagens de seu autor e de seu espectador intercaladas no texto; ou seja, seus contratos de leitura). Interessa-nos reconstruir a estrutura e os processos do objeto investigado em termos qualitativos. (CASETTI; CHIO, 2013, p. 249-250).

Aos objetivos deste trabalho, vamos emprestar de Casetti e Chio apenas os dois passos iniciais do método. Ou seja, veremos os aspectos relativos aos sujeitos presentes em cena e às interações que ali tiveram lugar, assim como aos textos verbais presentes nesta interação. Focaremos o segmento de 10 minutos de diálogo entre o analista Forbes e sua interlocutora, a atriz Maria Fernanda Cândido, no episódio Você tem medo de que? (TERRA DOIS, 2017). A produção, levada ao ar em junho de 2017 e desde então disponível nos acervos do Youtube, foi escolhida por abordar um tema universalizante, não associado às questões de gênero ou faixa etária, e de competência típica do campo da psicanálise.

Para efeito de uma melhor compreensão do seriado, cabe destacar que o objetivo central do programa é analisar experiências dramatizadas à luz de um mundo marcado pela desregulamentação e abandono de tradições e convenções, no espírito da metáfora da liquidez baumaniana. Cada episódio aborda um tema de caráter existencial ao longo 
de três blocos que perfazem um total de 45 minutos, alternando imagens coloridas e em preto e branco segundo a proposta estética para o formato.

O primeiro bloco cumpre a função de introduzir o tema que será tratado no episódio, com um diálogo inicial, na primeira temporada, entre Forbes (JF) e Maria Fernanda Cândido (MFC). Sentados em cadeiras tipicamente utilizadas por diretores de cinema, um frente ao outro, eles travam diálogos em que a atriz se coloca como um espectador comum, fazendo reflexões e sinalizando temas que serão objeto dos comentários do estudioso, momento em que ele apresenta sua tese psicanalítica para o episódio em questão. Neste caso, Forbes sustenta que o medo existencial, associado ao medo que movimenta toda a indústria da segurança, decorre de uma pós-modernidade que abandonou sólidas referências da era moderna. "Se a gente conseguir, neste episódio, mostrar para as pessoas que todos nós caímos numa armadilha do medo, que todos nós colocamos o medo como organizador das nossas vidas, será um trunfo incrível”, pondera ele. A interlocução neste primeiro bloco é intercalada por imagens aceleradas de reuniões da equipe, preparação de cenário e ensaio dos protagonistas da dramatização que terá lugar no segundo bloco.

O bloco seguinte é inteiramente dedicado à dramaturgia. Minimalista, o cenário transparente insinua espaços/cômodos em que os atores se movimentam e vivenciam conflitos, travando diálogos que serão objeto de análise no terceiro bloco. No episódio selecionado, o elemento dramático é o acalorado debate entre dois atores de teatro vividos por Eucir de Souza e Rodrigo Bolzan, travado ainda no camarim, momentos antes de encenarem uma peça havia três anos em cartaz. Um deles está incomodado com a mesmice da vida que leva, enquanto o outro se mostra satisfeito com o fato de ser diariamente aplaudido por uma plateia sempre crescente, o que lhe garante pagar as contas do mês. Ao final da discussão sobre os medos que enfrentam e prestes a assumirem seus papéis no palco, um dos personagens olha para a câmera e interroga o espectador: "E você, tem medo de que?".

Nosso recorte se voltará apenas para uma parte do último bloco, com dez minutos de duração. Depois do intervalo, a vinheta reintroduz os condutores do seriado. Forbes e Maria Fernanda, nos bastidores, aparecem sentados ao redor uma mesa branca, onde se vê papéis, caneta e dois copos com água pela metade. Eles observam a tela de 
um monitor pelo qual estariam assistindo à narrativa que acabou de ser levada ao ar. Ao fundo, na penumbra, veem-se objetos cênicos que remetem ao ambiente de trabalho dos artistas de televisão. Deste último bloco, extraímos alguns excertos do diálogo entre eles, suficientes para que possamos compreender os sentidos da análise elaborada:

\section{MFC: Amei este episódio}

JF: Eu acho interessante ver que o episódio, ele chama a atenção para a ideia da providência. A providência acalma as pessoas: saber que alguém zela pela gente. Em Terra Dois existe uma passagem de um mundo providencial, que é Terra Um, onde o pai zelava pelo filho na família, o chefe pelo subordinado, a pátria pelos seus cidadãos... Essa ideia de providência deixa de ter a mesma consistência, e as pessoas se sentem muito... muito perdidas, muito de-sas-sis-ti-das [soletrando em sílabas]. Porque você não ter uma ideia clara de o que você vai fazer, não ter um cardápio do seu dia, faz com que você ache que ninguém te deu o roteiro. Então as pessoas utilizam o medo quase como um novo organizador.

JF: Criar é você suportar o novo, criar é arriscar, criar é transformar sonho em realidade, criar é inventar. Imagina Santos Dumond com medo! [...] A ética do medo vai contra a ética do desejo. Ela [a ética do medo] é mais garantida, ela é mais ponto de referência, mas ela é empobrecedora da experiência humana.

JF: Em Terra Um existe o piloto automático. Você sabia como nascer, como se desenvolver, trabalhar, criar família e morrer. E hoje em dia, tá tudo embaralhado. Então, quebrou. O piloto automático quebrou. Terra Dois não tem, e a cada momento você tem que ficar corrigindo sua rota. Ou melhor, escolhendo uma rota.

MFC: Pra resumir um pouco essa coisa do medo, a gente podia citar Platão, que diz que nós podemos facilmente perdoar uma criança que tem medo do escuro, mas a real tragédia da vida é quando os homens têm medo da luz.

JF: Me recuso a qualquer comentário depois de Platão.

Risos.

É importante apontar que, neste bloco, algumas cenas da dramaturgia são reiteradamente reprisadas durante os comentários, funcionando como ilustrações que confirmam as análises de Forbes. O psicanalista e sua interlocutora esmiúçam diálogos dos personagens, sugerindo que na pós-modernidade prevalece a insegurança, a falta de referências e a incompletude das quais haviam falado no bloco inicial. Ao longo das leituras psicanalíticas, quatro formulações verbais utilizadas pelo analista aparecem grafadas no centro da tela em letras garrafais, sempre entrecortadas pela barra vertical 
que caracteriza o mundo particionado. São elas: "providência"; "medo é conservador"; "medo é antídoto da criatividade"; e "invenção do futuro".

Coincidência ou não, Bauman, autor citado por Maria Fernanda Cândido ao participar de uma entrevista com o mesmo psicanalista no programa Roda Viva, da mesma emissora, tem uma obra inteiramente dedicada ao fenômeno do medo (BAUMAN, 2006) e outra dedicada à (in)segurança e medo nas cidades (BAUMAN, 2009). Mas o medo de que fala o sociólogo alemão decorre da nossa fragilidade frente à onipotência do capital, frente às armadilhas da sociedade do livre mercado, frente à globalização que teria transformado as cidades em "depósitos de problemas" (2009, p. 32) ou, em especial, ao "pavor da morte" (2006, p.35). Com Forbes, o viés psicanalítico aponta que o medo resulta de nossa inadequação ao mundo exterior.

Quando grafa em maiúsculas a expressão "providência", o discurso de Forbes remete a uma era - de acordo com ele, a caminho do fim - quando prevalecia certa responsabilidade para com a vida do outro, seja este outro um filho, um subordinado ou um compatriota. O episódio aqui referido de Terra Dois, de alguma maneira, decreta o fim da solidariedade, acolhendo o egocentrismo e o hedonismo como traços permanentes da nova cultura. Se não se pode contar com ninguém, ninguém se sentirá no compromisso ético de fornecer abrigo, de amparar ou ter compaixão.

Fica também sugerida que a superação dos entraves que os novos tempos (neoliberais?) irão impor aos habitantes de Terra Dois será possível com a criatividade, o esforço individual, a autossuperação. Trata-se de "inventar um futuro" - como grafado em letras maiúsculas - particular, que supere as adversidades de condições objetivas desfavoráveis. No episódio, fica implicitamente sugerido que a adesão resiliente ao novo paradigma é o caminho adequado para uma existência menos conflituosa, obrigando a uma travessia com a qual a psicanálise teria muito a colaborar.

Resistência e crítica, no entanto, não têm lugar em Terra Dois. Não há ressalvas à ordem econômica que produz os processos de exclusão e que, em larga medida, dá origem aos maiores medos na sociedade contemporânea: a violência física e o desemprego, problemas que só se ampliam à medida que se aprofundam as políticas neoliberais em curso. Como lembra o próprio Bauman, no mundo do desemprego estrutural em que já estamos mergulhados, 
Ninguém pode razoavelmente supor que está garantido contra a nova rodada de "redução de tamanho", "agilização" e "racionalização", contra mudanças erráticas da demanda do mercado e pressões caprichosas mas irresistíveis de "competitividade", "produtividade" e

“eficácia”. (BAUMAN, 2001, p. 185).

Para este autor, a flexibilidade que se festeja em uma sociedade livre das regulamentações do trabalho equivale a não mais que "empregos sem segurança, compromissos ou direitos, que oferece apenas contratos a prazo fixo ou renováveis, demissão sem aviso prévio e nenhum direito à compensação" (BAUMAN, 2001, p. 185). Ao debruçar-se sobre o tema, em $O$ mal estar da pós-modernidade (BAUMAN, 1998), o autor pontua as dramáticas consequências sociais, econômicas, morais e psicológicas decorrentes deste processo de fragilização da mão de obra em detrimento da supremacia do capital, um fenômeno que não se registra apenas nas economias periféricas.

No universo psicanalítico de Terra Dois, resistência e crítica cedem lugar à resiliência, expressão de vários significados, mas que na Psicologia pode ser entendida como a reconfiguração interna do sujeito diante de adversidades ou traumas, com potencial para levar ao crescimento ou desenvolvimento pessoal (BARLACH, 2005). Não é sem razão, portanto, que, no capítulo em pauta, Platão é recuperado para lembrar ao espectador a importância que o conhecimento adquire ao longo de nossas existências. Conhecimento este que o seriado se propõe a fornecer através da antecipação, mesmo que dramatizada, de experiências de vida diante de uma mudança paradigmática das proporções ali anunciadas.

\section{Considerações finais}

Pretendemos com este trabalho evidenciar a assertiva de Luhmann sobre a dinâmica dos sistemas de função - neste caso, a ciência do comportamento no campo da psicanálise lacanina- confrontando a sociedade com os novos problemas advindos do processo civilizatório. Trata-se aqui da emergência de um novo estatuto paradigmático, que tem inspirado o sistema científico a uma extensa produção bibliográfica, oriunda das mais diversas matizes do pensamento contemporâneo. 
Neste sentido, enquanto produção da cultura da mídia, Terra Dois procura desempenhar o papel que antes cabia ao mito e aos rituais, como propõe Kellner, de integrar indivíduos a uma determinada ordem social, oferecendo valores, experiências e modelos a serem seguidos. Ao abordar uma nova ordem, ainda em construção, o seriado da TV Cultura se apresenta como um norte de bússola no universo "desbussolado", como refere Forbes, do mundo contemporâneo.

Para cumprir sua função, o seriado faz uso do conhecimento científico para iluminar experiências de vida que antecipará ao público. Em se tratando de uma produção típica da primeira fase da televisão, adota uma linguagem prescritiva e pedagógica ao propor o exercício da resiliência aos espectadores do programa, aos quais lança o desafio de abandonar uma âncora que cumpriu sua função para lançar-se a um mundo que está por se construir.

Enquanto produção televisiva que mistura informação científica e dramaturgia, o trabalho da equipe comandada por Forbes foi reconhecido pelos membros da Academia Paulista dos Críticos de Arte (APCA) como o melhor programa da televisão brasileira no ano de 2017. Nem por isso, deixou de registrar apenas traços quando se fala em índice de audiência. Mesmo no Youtube, o episódio Você tem medo de que? sequer chegou a atingir 5 mil visualizações um ano após ali ter sido postado. Esse aparente paradoxo nos remete às reflexões de Bourdieu (1997), segundo quem o reconhecimento pelos pares (neste caso, o meio artístico) quase nunca caminha na direção das predileções do mercado, que se apega aos índices de audiência para financiar as produções culturais.

\section{Referências}

ARONCHI, José Carlos. Debate: Televisão, Gêneros e Linguagens. Rio de Janeiro: Salto para o Futuro, 2006

BARLACH, Lisete. O que é resiliência humana?: Uma contribuição para a construção do conceito. Dissertação (Mestrado). 118 f. Curso de Psicologia, Universidade de São Paulo, São Paulo, 2005.

BAUMAN, Zygmunt. O mal-estar da pós-modernidade. Rio de Janeiro: Jorge Zahar, 1998.

Modernidade líquida. Trad. Plínio Dentzien. Rio de Janeiro: Zahar, 2001. 2006.

Medo líquido. Trad. Carlos Alberto Medeiros. Rio de Janeiro: Jorge Zahar Ed., 
Confiança e medo nas cidades. Trad. Eliana Aguiar. Rio de Janeiro: Jorge Zahar Ed., 2009.

BOURDIEU, Pierre. Sobre a televisão. Rio de Janeiro: Jorge Zahar, 1997. Tradução de: Maria Lúcia Machado.

CASETTI, Francesco; ODIN, Roger. Da Paleo à Neotelevisão: abordagem semiopragmática. Ciberlegenda, [S.1.], n. 27, dez. 2012, 8-22. Disponível em: $<$ http://www.ciberlegenda.uff.br/index.php/revista/article/view/596/339>. Acesso em: 24 jan. 2017.

CASETTI, Francesco; CHIO, Federico di. Análisis de la televisión: instrumentos, métodos y prácticas de investigación. $2^{\mathrm{a}}$ impressão. Barcelona: Paidós, 2013.

FELTRIN, Ricardo. Na Grande São Paulo, TV cultura cresce em audiência e abre distância da Rede TV!. Uol. Postado em: 20 Set. 2017. Disponível em: $<$ https://tvefamosos.uol.com.br/noticias/ooops/2017/08/20/na-grande-sp-tv-culturacresce-em-audiencia-e-abre-distancia-da-redetv.htm>. Acesso em: 15 Mar. 2018.

FORBES, Jorge. Sobre o programa Terra Dois: entrevista [22 Dez. 2017]. Entrevistadora: Hebe Rios do Carmo. São Paulo, 2017.

GIDDENS, Anthony. Modernidade e identidade. Trad. Plínio Dentzien. Rio de Janeiro: Jorge Zahar, 2002

KELLNER, Douglas. Media Spectacle. Califórnia: Routledge, 2003.

A cultura da mídia - estudos culturais: identidade e política entre o moderno e o pós-moderno. Trad. Ivone Castilho Benedetti. Bauru (SP): Edusc, 2001

LUHMANN, Niklás. A realidade dos meios de comunicação. São Paulo: Paulus, 2005. (Comunicação). Tradução de: Ciro Marcondes Filho.

MARCONDES FILHO, Ciro. Prefácio à edição brasileira: Niklás Luhmann, a comunicação vista por um novo olhar. In: LUHMANN, Niklás. A realidade dos meios de comunicação. Trad. Ciro Marcondes Filho. São Paulo: Paulus, 2005.

TERRA DOIS. Você tem medo de que? TV Cultura São Paulo. Youtube. Postado em: 5 Jun. 2017. Disponível em: <https://www.youtube.com/watch?v=3ZRIXszs_7k>. Acesso em: 12 Jan. 2018

THOMPSON, John B.. A mídia e a modernidade: uma teoria da comunicação linear e em rede. 5. ed. Petrópolis, Rj: Vozes, 1998. 